Research Article

\title{
The Influence of Complexity of Imported Products on Total Factor Productivity
}

\author{
Nan Wang, ${ }^{1,2}$ Wei Liu, ${ }^{2,3}$ Shanwu Sun, ${ }^{1,2}$ and Qingjun Wang ${ }^{4}{ }^{4}$ \\ ${ }^{1}$ School of Management Science and Information Engineering, Jilin University of Finance and Economics, \\ Changchun 130117, China \\ ${ }^{2}$ Jilin Provincial Key Laboratory on Logistic Industrial Economy and Intelligent Logistics, \\ Jilin University of Finance and Economics, Changchun 130117, China \\ ${ }^{3}$ Editorial Office of Contemporary Economic Research, Jilin University of Finance and Economics, Changchun 130117, China \\ ${ }^{4}$ School of Economics and Management, Shenyang Aerospace University, Shenyang 110136, China
}

Correspondence should be addressed to Qingjun Wang; wangqingjun@sau.edu.cn

Received 19 July 2021; Revised 17 August 2021; Accepted 30 August 2021; Published 9 September 2021

Academic Editor: Sang-Bing Tsai

Copyright (c) 2021 Nan Wang et al. This is an open access article distributed under the Creative Commons Attribution License, which permits unrestricted use, distribution, and reproduction in any medium, provided the original work is properly cited.

The research results show that, all over the world, the increase in complexity of China's imported products has significantly promoted the growth of total factor productivity and technological progress but has no obvious impact on technological efficiency. In "Belt and Road" samples, the increase in import product complexity did not improve the total factor productivity and technological progress, which had a negative impact on technical efficiency. Whether it is anywhere in the world or in the scope of "Belt and Road" countries, the import product density has a significantly positive impact on total factor productivity but has no significant effect on the promotion of technological progress and efficiency. Therefore, it is necessary to focus on adjusting the import trade structure of "Belt and Road" countries. Relying on the domestic consumer market, the manufacturing imports from countries along the "Belt and Road" route should be expanded so as to stimulate the promotion of domestic industrial total factor productivity.

\section{Introduction}

In the context of globalization, the spillover effects and the research and development externalities, as channels for total factor productivity growth, brought by import trade, have been one of the major issues under discussion in international trade in the past decades. At the same time, China put forward "Belt and Road" (B\&R) initiative in 2013, and it is of more practical and theoretical significance to study the impact of the trade of importing from countries along "Belt and Road" (B\&R countries) on the total factor productivity of domestic industries. At present, the literature mainly focuses on the research of imported intermediate products and the types of imported products or the analysis of total factor productivity with import data at the enterprise level. However, both variety model [1] and quality ladder model $[2,3]$ assumed that there was homogeneity between products and that the initial specialization of one product did not affect the productivity level of another product. However, Hausmann and Klinger considered that the products are highly heterogeneous [4]. They argued that producing (exporting) some kinds of products will have a higher spillover effect than other products.

It is not difficult to find that the influence of import trade on total factor productivity is concluded differently at different levels. From the perspective of import, this paper demonstrates the impact of the import product complexity and density by China around the world on total factor productivity and the impact of the import product complexity and density by China from "B\&R" countries on total factor productivity. On the basis of pertinent literature, which analyzes the role of import trade in improving total factor productivity, based on the influence of analysis of import product complexity and density on total factor 
productivity, the import complexity is divided into global sample and "B\&R" sample, to analyze the similarities and differences of the influences of global import complexity, and "B\&R" import complexity on China's total factor productivity.

\section{Theoretical Model}

Although import trade, as a technology spillover, has been recognized by many scholars, the developing countries need some suitability to improve technology level or total factor productivity through import channels. If the importing country cannot introduce technologies which are appropriate to its factor endowment structure, then, it may not achieve the productivity consistent with that of the exporting country [5]. At the same time, if it is related to more complex and advanced regional products in product space $[6,7]$, this will promote the importing country to produce more complex products. Subsequently, producing more complex products will promote the improvement of total factor productivity in the industry, and producing a product with higher complexity will have a favorable impact on the production growth rate, because it will increase the accumulation of human capital. This paper constructs the analysis framework of "complexity spillover regression of imported products," in each country $c=1,2, \ldots \ldots, n$, the size of labor force is fixed at $L_{c}$ level, and the average human capital level of country $c$ is $h_{c}$ (for simplicity, $h_{c}$ is assumed to be constant across all industries). The share of human capital allocated to production in nonleisure time is $\lambda_{c}\left(\lambda_{c} \in[0,1]\right)$, and the share $1-\lambda_{c}$ is the leisure time used for the accumulation of human capital. Long-term investment in human capital is a key driving factor of economic growth. Assuming that the fixed capital is $K$, the complexity spillover of imported products is $e^{\alpha_{c} z^{i}}$, the produced products are represented by $Q$, then, the production function is Cobb-Douglas production equation; that is,

$$
Q_{c}^{i}=\lambda_{c} h_{c} K e^{\alpha_{c} z^{i}} .
$$

In each country, there is a continuous industry $i$, which is evenly distributed in the unit interval $[0,1]: i \sim U[0,1]$. Each industry feature is represented by the parameter $z_{i}\left(z_{i}>0\right)$, which represents the imported technological complexity of the industry. The complexity of the import industry also determines the location of the country's product space, while it is linked to more advanced production technologies. Higher complexity means a related division of labor, therefore involving an increase in the number of tasks in the production process. In this regard, increasingly complex tasks may lead to the benefits of specialization division, but the high complexity of imports may also reduce their initiative to produce or have an impact on domestic capital allocation.

The production equation is an increasing function assigned to the current production share $\lambda_{c}$ and human capital level $h_{c}$ over time and also a function of the complexity $z^{i}$ of import industry $i$. The parameter $\alpha_{c}$ influences the import industry complexity through the formula $\alpha_{c}=\theta_{c}-\delta_{c}$. When $\theta_{c} \geq 0$, then, it shows that the complexity of import industry is consistent with the suitability of domestic resource endowment or human capital, and import complexity can be well absorbed and transformed by the domestic market. So, the import product complexity can potentially actively promote the growth of total factor productivity in the industry, such as the shared human capital, fixed costs, legal system, and market knowledge. $\delta_{c} \geq 0$ expresses the possible negative effects. For example, although the import product complexity encourages domestic industries to learn and imitate, this kind of complementary production (imitation learning) may bring some risk of production failure, or import complexity does not have appropriate capacity to absorb in domestic. From the perspective of resource allocation, it is a waste, which will have a negative impact on the domestic market. In principle, $\alpha_{c}(\prec / \succ) 0$ depends on the total effects of the import product complexity, previously analyzed, on total factor productivity.

$\varphi_{c}\left(z^{i}\right)$ is the complex density function of a country $c$, and the total output of this country $c$ is

$$
Q_{c}=L_{c} K_{c} \int_{0}^{\infty} \varphi_{c}\left(z^{i}\right) \mathrm{d} z^{i}
$$

For analysis purpose, this paper assumes that the industrial complexity $z^{i}$ of imports in country $c$ obeys the general gamma distribution: $z^{i} \sim \operatorname{Gamma}\left(K_{c}, \beta_{c}\right)$, and meanwhile, the parameters $K_{c}>0$ and $\beta_{c}>0$, as shown in the following:

$$
\varphi_{c}\left(z^{i}\right)=\frac{1}{\beta_{c}^{k_{c}} \Gamma\left(k_{c}\right)}\left(z^{i}\right)^{k_{c}-1} e^{-z^{i} / \beta_{c}} .
$$

From the properties of gamma distribution, the average complexity of the country $c$ is $z_{c}=E_{c}\left(z^{i}\right)=k_{c} \beta_{c}$, the variable $V_{c}\left(z^{i}\right)=k_{c} \beta_{c}^{2}$, and the skewness of the density function of its variance is $2 / \sqrt{k_{c}}$, in which $k_{c}$ denotes to parameter shape and $\beta_{c}$ is the scale parameter of Gamma distribution. $k_{c}$ can be interpreted as the shape coefficient of technical parameters and industrial production characteristics. In each country, $k_{c}=k, c=1,2, \ldots, n$, and parameter $\beta_{c}$ has the effect of replacing horizontally and vertically scaled graphics, which is related to the specific distribution of complexity in each country, so every country is unique. The average import complexity of a country $c$ is $z_{c}=k_{c} \beta_{c}$.

Substituting (1) and (3) into (2), the output level of a country $c$ can be expressed as follows:

$$
Q_{c}=L_{c} \lambda_{c} h_{c} \times \frac{1}{\left(1-\alpha_{c} \beta_{c}\right)^{k}} .
$$

According to (4), it can be concluded that the influence of the import complexity variable $\beta_{c}$ of the function is uncertain and depends on the parameters $\alpha_{c}=\theta_{c}-\delta_{c}$. If the import density effect of product space is a positive effect on the import complexity, then $\alpha_{c}>0$ and the import complexity with higher density relation corresponds to the increase of output. On the contrary, if import density and import complexity are negative effects, according to O-ring theory, higher import complexity leads to lower output level. 
The human capital formation equation is shown as follows [8]:

$$
\dot{h}_{c}=\mu_{c}\left(1-\lambda_{c}\right) z_{c} h_{c},
$$

where $\mu_{c}>0$ represents the effectiveness of the human capital training system in the country $c$. According to the initial level of human capital, compared with Lucas' human capital model, now, the formation of human capital includes importing average complex $Z_{c}$ as one of the parameters of accumulation equation.

The output growth is

$$
\begin{aligned}
\frac{\mathrm{d} Q_{c}}{\mathrm{~d} t}= & L_{c} \lambda_{c} \cdot \frac{1}{\left(1-\alpha_{c} \beta_{c}\right)^{k}} \times \frac{\mathrm{d} h_{c}}{\mathrm{~d} t}=L_{c} \lambda_{c} \cdot \frac{1}{\left(1-\alpha_{c} \beta_{c}\right)^{k}} \\
& \times \mu_{c}\left(1-\lambda_{c}\right) z_{c} h_{c} .
\end{aligned}
$$

The instantaneous output growth rate is

$$
g_{c} \equiv \frac{\mathrm{d} Q_{c}}{\mathrm{~d} t} \times \frac{1}{Q_{c}}=\mu_{c}\left(1-\lambda_{c}\right) z_{c}=\mu_{c}\left(1-\lambda_{c}\right) k \beta_{c}=\frac{\dot{h_{c}}}{h_{c}} .
$$

The total factor productivity growth is

$$
\mathrm{TFP}=e^{\alpha_{c} z^{i}}=\frac{1}{\left(1-\alpha_{c} \beta_{c}\right)^{k}} \text {. }
$$

According to total factor productivity (8), in the production function $\alpha_{c}=\theta_{c}-\delta_{c}$, if the $\alpha_{c}$ is negative, the increased import complexity has a negative impact on total factor productivity. In other words, if $\theta_{c}<\delta_{c}$, the benefit of specialization plays a dominant role in the O-ring. On the contrary, it has a positive impact on total factor productivity, which will be tested by empirical analysis.

\section{Data Measurement and Variable Selection}

3.1. Measurement of Total Factor Productivity. Van Beveren and Tian et al. tested the "consistency" and "robustness" of the results of different TFP measurement methods and found that if the panel data is based on the macroindustry, compared with the parametric method SFA, the nonparametric method DEA is a more suitable measurement method $[9,10]$. Therefore, this paper used DEA-Malmquist method for calculation.

The paper adopts traditional double input and single output model to calculate total factor productivity, including capital input and labor input, and the output is expressed as industrial added value. Among them, capital input is measured by capital stock. Since capital stock is different from output and labor data that may be obtained directly, it is required to make scientific estimation. According to the existing literature, the capital stock is estimated by the general perpetual inventory method $[11,12]$.

3.2. Calculation of Import Industry Complexity. Tian et al. proposed to calculate product complexity by nonlinear fitness iteration method [10]. The fitness method involves two steps: first, work out the intermediate variables $\widetilde{F}_{c}^{(n)}$ and
$\widetilde{Q}^{(n)}$, and then, standardize them. The initial condition is $\widetilde{F}_{c}^{(0)}=1 \forall c$ and $\widetilde{Q}_{p}^{(0)}=1 \forall p$. If the country $c$ exports the product $p$ with revealed comparative advantage, then, $M_{c p}=1$; otherwise, $M_{c p}=0$. The simplest way to do this is by using the following formula. First, the intermediate variables $\widetilde{F}_{c}^{(n)}$ and $\widetilde{Q}_{p}^{(n)}$ are calculated:

$$
\widetilde{F}_{c}^{(n)}=\sum_{p} M_{c p} Q_{p}^{n-1}, \widetilde{Q}_{p}^{(n)}=\frac{1}{\sum_{c} M_{c p}\left(1 / F_{c}^{(n-1)}\right)} .
$$

Then, the national adaptability and product complexity are defined:

$$
\begin{aligned}
F_{c}^{(n)} & =\frac{\widetilde{F}_{c}^{(n)}}{\left\langle\widetilde{F}_{c}^{(n)}\right\rangle_{c}}, \\
Q_{p}^{(n)} & =\frac{\widetilde{Q}_{p}^{(n)}}{\left\langle\widetilde{Q}_{p}^{(n)}\right\rangle_{p}},
\end{aligned}
$$

where $F$ represents the national fitness (complexity) level, $Q$ represents product complexity, and $M_{c p}$ has the same meaning as reflection method. $\left\langle\widetilde{F}_{c}^{(n)}\right\rangle_{c}$ and $\left\langle\widetilde{Q}_{p}^{(n)}\right\rangle_{p}$ is the average of product complexity and national fitness during each iteration. Compared with reflection method, Tacchella method has the following advantages: the calculation results of reflection method tend to converge, and the calculation results of Tacchella method are more divergent, making it easier to distinguish between national fitness and product complexity. Compared to the reflection method, Tacchella method does not undermine the relationship between national capabilities and product complexity. In reflection method, the variables $K_{c}$ and $K_{p}$ cannot be properly measured and reflect product complexity. However, in the Tacchella method, $\widetilde{F}_{c}^{(n)}$ can more accurately measure the property represented by $\widetilde{Q}_{p}^{(n)}[13]$.

If $\mathrm{Com}_{p}^{i t}$ denotes the product complexity, Comim ${ }_{i t}$ denotes the complexity of import industry, and then, its calculation equation is as follows:

$$
\operatorname{Comim}_{i t}=\sum_{p=1}^{n} \operatorname{Com}_{p}^{i t} \times \frac{\operatorname{Im}_{p}^{i t}}{\operatorname{Im}^{i t}},
$$

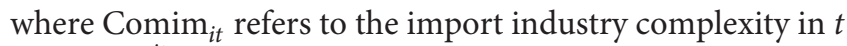
year, $\mathrm{Com}_{p}^{i t}$ refers to the import product complexity in $t$ year, $\mathrm{Im}_{p}^{i t}$ refers to the total trade volume of imported products $p$ in $t$ year, and $\mathrm{Im}^{i t}$ refers to the total import trade volume of $i$ industry in $t$ year. According to (11), import product $p$ is multiplied by the complexity of product $p$ according to the weight of the total import industry volume, and then, all the product complexity values included in industry $i$ are assigned according to the weight and summarized to obtain the industrial complexity.

3.3. Industrial Input and Output Data Selection and Processing. In this paper, the industrial division is based on the classification of China Statistical Yearbook, and the industrial data mainly originate from the China Statistical Yearbook, the China Industry Economy Statistical 
Yearbook, the China Economic Census Yearbook, provincial statistical yearbooks, the China Labor Statistical Yearbook, and the websites of the National Bureau of Statistics of the People's Republic of China in 1999-2016.

The paper adopts traditional double input and single output model to calculate the total factor productivity, including capital input and labor input, and the output is expressed as industrial added value. Among them, capital input is measured by capital stock. Since capital stock is different from output and labor data that may be obtained directly, it is required to make scientific estimation. According to the existing literature, the capital stock is estimated by the general perpetual inventory method $[11,12]$. Considering the availability of data, this paper takes the average annual number of employees in the industry to represent the labor input. Since the number of employees in the industry from 2012-2014 is no longer available in the China Statistical Yearbook, it is summarized according to the data of different industries in the China Labor Statistical Yearbook. Since 2012, the state divided "rubber and plastic product industry" into "rubber product industry" and "plastic product industry." However, considering that only three years of new industry division standards are involved in the data used in this study, the state still divides and merges the industry division standards of 2002 accordingly. The industrial added value in 2004 is calculated according to the proportion of total industrial output value in 2003 and 2004 .

\section{Econometric Model Analysis}

4.1. Setting of the Econometric Model. According to the research objective, the paper set the model as two basic econometric models:

$$
\begin{aligned}
\ln g_{i, t}= & \alpha_{0}+\beta_{0} L \cdot \ln g_{i, t}+\beta_{1} L \cdot \ln \mathrm{ICom}_{i, t} \\
& +\beta_{2} L \cdot \ln \mathrm{immidu}+\gamma \operatorname{Contr}+\eta_{i}+\varepsilon_{i, t}, \\
\ln g_{i, t}= & \alpha_{0}+\beta_{0} L \cdot \ln g_{i, t}+\beta_{1} L \cdot \ln \text { yyICom }{ }_{i, t} \\
& +\beta_{2} L \cdot \ln y y i m m i d u+\gamma \operatorname{Contr}+\eta_{i}+\varepsilon_{i, t},
\end{aligned}
$$

where $\ln g_{i, t}$ denotes the logarithm of productivity growth rate, which is expressed as the logarithms of total factor productivity (TFP), technical change (TC), and technological efficiency (TE), respectively, $i$ denotes 34 industries, and $\ln g_{i, t-1}$ denotes the productivity growth rate of one lagged stage. $t$ refers to the year. In model equation (12), ICom is the import industry complexity and immidu is the import product density. In model equation (13), $\mathrm{ICom}_{i, t}$ is the import industry complexity from countries along the "Belt and Road," and yyimmi duis the density of importing products from countries along the "Belt and Road." Contr is the control variable, including import permeability, export permeability, R\&D density, enterprise scale, and capital density. $\eta_{i}$ and $\varepsilon_{i, t}$ reflect the individual effect of differences in various industries and other disturbance terms.

4.2. Variable Selection. The main explanatory variables are import product complexity (ICom) and imported product density (immidu). The import product complexity was figured out using the fitness method [13] and the reflection method in robustness test [6]. Regarding the product density, the closer the distance between product and superior product is, the more easily the transformation will succeed. A higher import product density indicates it is more suitable for domestic technological absorption, thus facilitating the increase of domestic total factor productivity.

Other control variables include the following. R\&D Density $(r d)$. The R\&D input behavior not only influences the total factor productivity but also affects product complexity. Taking the logarithm of the ratio of "total internal expenditure of technological development funds" and the total output value over the years as the substitution variable of $\mathrm{R} \& \mathrm{D}$ technology, the $\mathrm{R} \& \mathrm{D}$ density is expressed as $\ln (\mathrm{R} \& \mathrm{D} / Y+1)$. Export Permeability (imrat). The enterprise can get a greater learning effect by export, further promoting the increase of total factor productivity and technical change. Export permeability is the ratio of the export/import amount to the total output of the industry. Import Permeability (exrat). The industrial trade liberalization may have effect on total factor productivity of industry. Referring to the practice of [14], the paper used import permeability to represent the degree of industrial trade liberalization, so as to control its influence on industrial total factor. Enterprise Scale (qygm). The enterprise scale is considered one of the important factors affecting enterprise productivity. In this paper, the enterprise scale is expressed by the ratio between the constant added value of industry and the number of enterprises in the industry. Capital Density (zblab). The capital density can control its impact on total factor productivity and can eliminate the impact of national scale. Dividing the amount of capital invested in each industry by the number of people employed, we can take capital density $\ln (K / L+1)$ and put it into equation.

4.3. Empirical Analysis. In Table 1, equations (1)-(3) are the regression result of product complexity imported by China from all over the world, and equations (4) and (5) are the regression result of product complexity imported by China from "B\&R" countries. The dependent variables of equations (1) and (4) are total factor growth index, the dependent variables of equations (2) and (5) are technology progress growth index, and the dependent variables of equations (3) and (6) are technology efficiency growth index. From the perspective of equations (1)-(3), the increase in the complexity of imported products worldwide can promote the growth of Malmquist productivity and technological progress, but the impact on technical efficiency is not significant. The import product density promotes the growth of total factor productivity but has no significant impact on technical progress and technological efficiency. Both export permeability and import permeability promote productivity and technological progress; research and development investment has a significant positive impact on the total factor and nonsignificant negative impact on technical efficiency, but it significantly promotes the growth of technological progress; enterprise scale has a negative influence on 
TABLE 1: The influence of import complexity on total factor productivity.

\begin{tabular}{|c|c|c|c|c|c|c|}
\hline & (1) MI & (2) TC & (3) EC & (4) $\mathrm{MI}$ & (5) $\mathrm{TC}$ & (6) EC \\
\hline L.MI & $\begin{array}{c}-0.389^{* * *} \\
(-8.163)\end{array}$ & & & $\begin{array}{c}-0.381^{* * *} \\
(-7.860)\end{array}$ & & \\
\hline L.TC & & $\begin{array}{c}-0.652^{* * *} \\
(-14.879)\end{array}$ & & & $\begin{array}{c}-0.642^{* * *} \\
(-14.352)\end{array}$ & \\
\hline L.EC & & & $\begin{array}{c}-0.371^{* * *} \\
(-9.179)\end{array}$ & & & $\begin{array}{c}-0.377^{* * *} \\
(-9.348)\end{array}$ \\
\hline L. $\operatorname{lnimcom}_{i, t}$ & $0.025^{*}(1.73)$ & $0.044^{* * *}(2.90)$ & $-0.02(-1.363)$ & & & \\
\hline $\begin{array}{l}\text { L. lnyyimcom } \\
\text { L. lnimmidu }\end{array}$ & $0.026^{*}(1.78)$ & $0.012(0.78)$ & $0.018(1.20)$ & $-0.013(-1.097)$ & $0.008(0.64)$ & $-0.023^{* *}(-2.001)$ \\
\hline L. lnyyimmidu & & & & $0.033^{* *}(2.16)$ & $0.018(1.13)$ & $0.017(1.16)$ \\
\hline Lnimrat & $0.047^{* * *}(3.49)$ & $0.032^{* *}(2.24)$ & $0(0.02)$ & & & \\
\hline Lnyyimrat & & & & $0.018(1.61)$ & $0.005(0.41)$ & $-0.003(-0.260)$ \\
\hline Lnexrat & $0.049^{* * *}(3.32)$ & $0.064^{* * *}(4.16)$ & $-0.007(-0.504)$ & & & \\
\hline Lnyyexrat & & & & $0.034^{* * *}(3.21)$ & $0.038^{* * *}(3.41)$ & $-0.001(-0.064)$ \\
\hline Lnqygm & $-0.023(-1.625)$ & $-0.016(-1.106)$ & $0(-0.005)$ & $\begin{array}{c}-0.039^{* * *} \\
(-2.823)\end{array}$ & $-0.036^{* *}(-2.458)$ & $0.007(0.55)$ \\
\hline Lnrd & $0.944(1.34)$ & $1.528^{* *}(2.06)$ & $-0.318(-0.449)$ & $1.367^{*}(1.92)$ & $1.978^{* * *}(2.64)$ & $-0.331(-0.474)$ \\
\hline Lnzblab & $0.065^{* *}(2.08)$ & $0.097^{* * *}(2.95)$ & $0(-0.000)$ & $0.023(0.77)$ & $0.047(1.48)$ & $0.003(0.09)$ \\
\hline _Cons & $1.631^{* * *}(15.28)$ & $1.943^{* * *}(18.02)$ & $1.281^{* * *}(14.12)$ & $1.527^{* * *}(14.12)$ & $1.850^{* * *}(16.86)$ & $1.239^{* * *}(13.47)$ \\
\hline $\bar{N}$ & 543 & 543 & 543 & 543 & 543 & 543 \\
\hline$r 2$ & 0.175 & 0.352 & 0.152 & 0.149 & 0.325 & 0.159 \\
\hline$r 2 \_a$ & 0.108 & 0.298 & 0.083 & 0.08 & 0.27 & 0.091 \\
\hline$F$ & 13.301 & 33.946 & 11.229 & 11.002 & 30.171 & 11.882 \\
\hline Model & $\mathrm{FE}$ & $\mathrm{FE}$ & $\mathrm{FE}$ & $\mathrm{FE}$ & $\mathrm{FE}$ & $\mathrm{FE}$ \\
\hline Scope & All over the world & All over the world & All over the world & "B\&R" & "B\&R" & "B\&R" \\
\hline
\end{tabular}

${ }^{* * *}$ and ${ }^{* * *}$ express $10 \%, 5 \%$, and $1 \%$ significant levels.

TABLE 2: The influence of import complexity on total factor productivity.

\begin{tabular}{|c|c|c|c|c|c|c|}
\hline & (1) MI & (2) TC & (3) EC & (4) MI & (5) TC & (6) EC \\
\hline L. MI & $\begin{array}{l}-0.381^{* * *} \\
(-7.936)\end{array}$ & & & $\begin{array}{l}-0.394^{* * *} \\
(-8.136)\end{array}$ & & \\
\hline L. TC & & $\begin{array}{l}-0.633^{* * *} \\
(-14.354)\end{array}$ & & & $\begin{array}{l}-0.645^{* * *} \\
(-14.366)\end{array}$ & \\
\hline L. EC & & & $\begin{array}{c}-0.370^{* * *} \\
(-9.224)\end{array}$ & & & $\begin{array}{c}-0.375^{* * *} \\
(-9.345)\end{array}$ \\
\hline L. $\operatorname{lnim} \operatorname{com}_{i, t}{ }^{(1)}$ & $0.031(1.21)$ & $0.071^{* * *}(2.64)$ & $\begin{array}{c}-0.079^{* * *} \\
(-3.140)\end{array}$ & & & \\
\hline L. lnyyimcom ${ }_{i, t}$ & & & & $\begin{array}{c}-0.038^{* * *} \\
(-2.683)\end{array}$ & $-0.013(-0.845)$ & $\begin{array}{c}-0.039^{* * *} \\
(-2.801)\end{array}$ \\
\hline L. lnimmidu & $0.027^{*}(1.81)$ & $0.013(0.86)$ & $0.017(1.13)$ & & & \\
\hline L. lnyyimmidu & & & & $0.030^{* *}(2.00)$ & $0.016(1.01)$ & $0.015(1.01)$ \\
\hline Lnimrat (yy) & $0.049^{* * *}(3.58)$ & $0.035^{* *}(2.46)$ & $-0.003(-0.237)$ & $0.032^{* * *}(2.64)$ & $0.016(1.24)$ & $0.006(0.50)$ \\
\hline Lnexrat (yy) & $0.050^{* * *}(3.40)$ & $0.067^{* * *}(4.33)$ & $-0.009(-0.624)$ & $0.034^{* * *}(3.24)$ & $0.038^{* * *}(3.42)$ & $-0.001(-0.101)$ \\
\hline Lnqygm & $-0.027^{*}(-1.964)$ & $-0.025^{*}(-1.700)$ & $0.005(0.34)$ & $-0.030^{* *}(-2.093)$ & $-0.032^{* *}(-2.100)$ & $0.016(1.15)$ \\
\hline Lnrd & $1.041(1.48)$ & $1.690^{* *}(2.28)$ & $-0.365(-0.521)$ & $1.232^{*}(1.74)$ & $1.948^{* * *}(2.59)$ & $-0.486(-0.696)$ \\
\hline Lnzblab & $0.060^{*}(1.92)$ & $0.089^{* * *}(2.73)$ & $0.002(0.07)$ & $0.033(1.11)$ & $0.05(1.58)$ & $0.015(0.51)$ \\
\hline _Cons & $1.591^{* * *}(15.48)$ & $1.878^{* * *}(18.23)$ & $1.260^{* * *}(14.44)$ & $1.549^{* * *}(14.72)$ & $1.832^{* * *}(17.16)$ & $1.261^{* * *}(14.13)$ \\
\hline $\mathrm{N}$ & 543 & 543 & 543 & 543 & 543 & 543 \\
\hline$r 2$ & 0.173 & 0.35 & 0.165 & 0.159 & 0.326 & 0.166 \\
\hline$r 2 \_a$ & 0.105 & 0.296 & 0.097 & 0.091 & 0.27 & 0.098 \\
\hline$F$ & 13.072 & 33.675 & 12.404 & 11.88 & 30.227 & 12.448 \\
\hline Model & $\mathrm{FE}$ & $\mathrm{FE}$ & $\mathrm{FE}$ & $\mathrm{FE}$ & $\mathrm{FE}$ & $\mathrm{FE}$ \\
\hline Scope & All over the world & All over the world & All over the world & "B\&R" & "B\&R" & "B\&R" \\
\hline
\end{tabular}


productivity and technological progress, and its influence on technical efficiency is approximately 0 ; capital intensity has a significant positive impact on productivity and technological progress, while its impact on technological efficiency is negative but not so significant.

From equations (4)-(6), the increase in complexity of importing products from "B\&R" countries does not have a significant effect on the growth of Malmquist productivity and technological progress and has a significantly negative on the technical efficiency. Similarly, the density of imported products promotes the growth of total factor productivity but does not significantly affect technological progress and efficiency. The import permeability of China and "B\&R" countries has no significant effect on the productivity, technological progress, and efficiency, while the export permeability has a significant effect on the productivity and technological progress but no significant effect on the technical efficiency. It is observed that the import product complexity and density plays a positive role to the total factor productivity. This demonstrates that China's importing products worldwide shows a higher technical level and complexity level, and this urges China to produce more complex products, propels the increase of total factor production of the industry, and brings beneficial impact on the production growth rate. At the same time, it is conducive to domestic technology absorption and technological progress, showing good technical suitability. However, the increase in import complexity of "B\&R" does not effectively promote the improvement of domestic total factor productivity, which indicates that the import trade structure of China and the "B\&R" needs to be adjusted to some extent. The density of imported products is also expressed as the structure of imported products, which is manifested as insignificant technological progress and efficiency, but has a promoting effect on total factor productivity. It indicates that the import product density mainly promotes the growth of total factor productivity by increasing resource allocation efficiency from the perspective of cost.

4.4. Robustness Test. Consider that the import complexity calculated by Tacchella et al. (2013) fitness method may have a bias on the total factor impact. In order to further verify the robustness of the model conclusion, the paper adopted the reflection method to regress the influence of import complexity on total factor productivity [13]. It can be seen from Table 2, that whether it is the entire sample or the sample of countries along "The Belt and Road," the results of the impact of import complexity on total factor productivity and the performance of the control variables are basically the same as those in Table 1. So, the conclusion of this paper can be proved to be robust.

\section{Conclusions}

This paper analyzes the effect of the import product complexity and density in promoting the growth of the total factor productivity. From the point of regression results, an increase in the complexity of China's imported products based on the samples all over the world significantly promotes the growth of the total factor productivity and technical progress, which demonstrates the technological progress is an investment used to improve people's knowledge and ability. However, the effect on promoting the technical efficiency is not obvious. The increase of import complexity based on "B\&R" samples did not promote the improvement of total factor productivity and had a significant negative impact on technical effect, indicating that the structure of importing "B\&R" products had no significant effect on the domestic technical progress. The import product density promotes the improvement of total factor productivity both all over the world and in "B\&R" countries, and the effect is basically the same. The specific performance shows that the structure of imported products plays a certain role in promoting the cost saving and allocative efficiency.

In this paper, the analysis results show that the increase in import complexity of China from countries along the "B\&R" route did not effectively promote the improvement of total factor productivity of the industry. The reason for this is that China mainly imports resources product or primary product from "B\&R" countries, leading to too much of domestic resources being taken up. So, when the government expands import trade from "B\&R" countries, it should pay attention to the composition of imported products, should fully respect the spontaneous market adjustment of economic resources, act as a good supporter and maker of market rules, make immediate policy adjustment to the import trade structure of "B\&R," and actively encourage to expand the import of manufacturing products from "B\&R" countries, such as labor-intensive consumer goods, which are the main export products of developing country and also the industry where China has gradually lost its comparative advantage. On the one hand, increasing the import of manufacturing products from "B\&R" countries can promote domestic productivity, and, on the other hand, "B\&R" countries can rely on China's large consumer market to drive the development of manufacturing industry in such countries and realize the common development and win-win cooperation.

\section{Data Availability}

The data underlying the results presented in the study are available within the manuscript.

\section{Conflicts of Interest}

The authors declare that they have no conflicts of interest.

\section{Acknowledgments}

This work was supported by the Key Project of Jilin Province Education Science during the 13th Five-Year Plan in 2020: Research on New Teaching Mode in Big Data Cloud Education Environment (ZD20024). 


\section{References}

[1] P. M. Romer, "Endogenous technical change," Journal of Political Economy, vol. 98, no. 5, pp. 71-102, 1990.

[2] P. Aghion and P. Howitt, "A model of growth through creative destruction," Econometrica, vol. 60, no. 2, pp. 323-351, 1992.

[3] G. M. Grossman and E. Helpman, "Quality ladders in the theory of growth," The Review of Economic Studies, vol. 58, no. 1, pp. 43-61, 1991.

[4] R. Hausmann and B. Klinger, "The structure of the product space and the evolution of comparative advantage," Harvard University, vol. 146, no. 2, 2007.

[5] D. Acemoglu, S. Johnson, and J. A. Robinson, "The colonial origins of comparative development: an empirical investigation," The American Economic Review, vol. 91, no. 5, pp. 1369-1401, 2001.

[6] R. Hausmann and C. Hidalgo, "Country diversification, product ubiquity and economic divergence," Harvard University, vol. 201, no. 11, 2010.

[7] B. Ferrarini and P. Scaramozzino, "The product space revisited: China's trade profile," The World Economy, vol. 38, no. 9 , pp. 1368-1386, 2015.

[8] R. E. Lucas, "On the mechanics of economic development," Journal of Monetary Economics, vol. 22, no. 1, pp. 3-42, 1988.

[9] I. Van Beveren, "Total factor productivity estimation: a practical review," Journal of Economic Surveys, vol. 26, no. 1, pp. 98-128, 2012.

[10] Y. Tian, S. Lu, and J. Laiqun, "Method, data and total factor productivity calculation difference," Quantitative and Technological Economy Research, vol. 12, pp. 22-40, 2017.

[11] J. Zhang, G. Wu, and J. Zhang, "Estimation of interprovincial physical capital stock: 1952-2000," Economic Research, vol. 10, pp. 35-44, 2004.

[12] S. Chen, "Estimation of statistical data of Chinese industry: 1980-2008," Economics, vol. 3, pp. 735-776, 2011.

[13] A. Tacchella, M. Cristelli, G. Caldarelli, A. Gabrielli, and L. Pietronero, "Economic complexity: conceptual grounding of a new metrics for global competitiveness," Journal of Economic Dynamics and Control, vol. 37, pp. 1683-1691, 2013.

[14] X. Qian, S. Wang, Y. Huang, and J. Wang, "Import variety and total factor productivity of China manufacturing industry," The World Economy, vol. 5, pp. 3-25, 2011. 